\title{
A REVIEW OF PROGRESSIVE COLLAPSE RESEARCH AND REGULATIONS
}

\author{
M. Byfield ${ }^{\mathrm{a}}$, G. L. Kasim ${ }^{\mathrm{a}}$, C. Morison ${ }^{\mathrm{b}}$ and E. Stoddart ${ }^{\mathrm{a}}$ \\ ${ }^{a}$ School of Civil Engineering and the Environment, University of Southampton, SO17 1BJ \\ ${ }^{\mathrm{b}}$ Security \& Explosion Effects Division, TPS Consult, Centre Tower, Croydon, CR9 OAU
}

\begin{abstract}
A series of historic events beginning with the Ronan Point apartment building collapse in 1968 and continuing in subsequent decades have shown that buildings designed in compliance with conventional design codes can lack the robustness necessary to withstand localised damage, partial collapse or, in some cases, complete collapse. The variable performance of different building forms has led to increased interest from governmental organisations in ensuring all buildings of significant size possess a minimum level of robustness. The research community have responded to this challenge by advancing the understanding of how structures behave when subjected to localised damage. Regulations and design recommendations have been developed to help ensure a more consistent level of resilience for all framed buildings of significant size and rigorous design approaches have been specified for buildings which are deemed potentially vulnerable to extreme loading events (e.g. vehicle borne improvised explosive devices). This paper summarizes some of the more important progressive collapse events in order to identify key attributes that lead to vulnerability to collapse. Current procedures and guidelines for ensuring a minimum level of performance are reviewed and the modelling methods developed for structures subjected to localised damage are described. These include increasingly sophisticated progressive collapse analysis procedures, starting with linear-static and non-linear static analysis and moving through to non-linear static pushover and linear dynamic methods. Finally the fully non-linear dynamic methods are considered. Building connections potentially represent the most vulnerable structural elements in steel framed buildings and their failure can lead to progressive collapses. Steel connections also present difficulties with respect to frame modelling and this paper highlights benefits and drawbacks of some modelling procedures with respect to their treatment of connections.
\end{abstract}

Keywords: Structures, progressive collapse, robustness, buildings, codes and standards, analysis, disproportionate collapse

\section{Introduction}

Interest in the progressive collapse of buildings was initiated after the partial collapse of Ronan Point in 1968 (Pearson and Delatte, 2005), which led to the first regulations with the aim of providing a minimum level of resistance to progressive collapse. The Ronan Point collapse was caused by a natural gas explosion, however blasts from car bombs, known as vehicle borne improvised explosive 
devices (VBIED) also have a proven ability to cause progressive collapses of buildings, such as the attack on the U.S. Marine Barracks in Beirut in 1983 which was almost completely demolished with the loss of 241 lives (Davis, 2007).

Localised structural weaknesses, sometimes combined with deterioration or overloading continue to cause collapses. Punching shear failures of flat slabs are the most common cause in reinforced concrete framed buildings, as occurred at the Pipers Row Car Park in Wolverhampton in the U.K. (1997) and at the Sampoong Superstore in South Korea (1995). In the Pipers Row Car Park, the loss of strength due to concrete deterioration triggered punching shear failures (Wood, 1997). In the Sampoong Superstore the inadequate provision of reinforcement in the flat slab column region, combined with over-loading caused punching shear failures and a collapse which killed 501 people (Wearne, 1999).

Buildings are always vulnerable to collapse during the construction phases, as occurred at the Skyline Tower in Virginia, in 1973. During construction shoring at the $22^{\text {nd }}$ floor was prematurely removed, causing punching shear failures which propagated throughout the full height of the building, a phenomenon sometimes referred to as pancaking. The impact from the debris also caused the collapse to progress sideways consuming an entire parking garage under construction adjacent to the tower. The L'Ambiance Plaza Building in Bridgeport, U.S. in 1987 also collapsed during the construction phase (Martin and Delatte, 2000). This involved the lift-slab method in which posttensioned concrete slabs were lifted onto steel column permanent supports. Three slab panels lifted to their temporary positions collapsed onto the permanent slab below due to substandard welding at slabto-column connections (McGuire, 1992; Ellingwood, 2007). The permanent slab was unable to resist the impact and collapsed, initiating a chain of collapses that progressed to the ground level (Martin and Delatte, 2000).

No review of progressive collapses would be complete without a mention of the 1995 Alfred P. Murrah Building collapse in Oklahoma City. The building featured open-plan architecture combined with a glazed façade, features that became vitally important when a VBIED was detonated on the curb side. The building comprised lightly reinforced columns common in non-seismic regions of the world. Such columns are vulnerable to shear failures due to the sideways pressure from blast loading and it is believed that the column closest to the blast shattered and the two columns either side failed in shear. Lacking strong internal partition walls or cladding, the building had no emergency means for redistributing loads and a progressive collapse was initiated which consumed nearly one half of the building, killing 168 people (Corley et al, 1998). The use of the transfer girder to support every other perimeter column has been widely attributed to the scale of the collapse, as has the lack of continuity of beam reinforcement through beam-column junctions. However, more recent forensic analysis of the building indicated that a $42 \mathrm{~m}$ wide section of the building would still have collapsed had all the perimeter columns been continued to ground floor level and had full reinforcement 
continuity been provided (in the actual event a $48 \mathrm{~m}$ wide section of the building collapsed) (Byfield and Paramasivam, 2012; NIST, 1995). This highlights the ease with which VBIED's can cause extensive column shear failures and also the importance of alternative load paths to redistribute loads away from damaged columns.

The Murrah Building can be contrasted with the response of framed buildings observed during World War II, some of which suffered loss of support at multiple perimeter columns. The forensic investigations into bomb sites led by Professor Sir Dermot Christopherson and Professor Lord Baker, found that progressive collapses were extremely rare for multi-storey framed buildings. This impressive robustness was attributed to the role that masonry infill panel walling and masonry facades played in supporting damaged columns through diagonal strutting action (Smith et al, 2012). The same mechanism was observed more recently following the explosion of a steam boiler which caused significant localized damage to a six-storey reinforced concrete framed office building (Sucuoglu and Altin, 1994).

The greater vulnerability of unframed loadbearing masonry construction to progressive collapse was illustrated by the attack on the Grand Hotel in Brighton in 1984. A 20-30 lb (9-14 kg) bomb in a bathroom on the sixth floor did not injure the occupants on the other side of the heavy masonry cross-wall, but the damage to the façade and timber floor above caused the roof to collapse locally, and the impact of debris collapsed all of the floors below into the basement. This progressive collapse was the primary cause of 5 deaths and 34 injuries.

In terms of the tragedy and losses, the above mentioned cases were far exceeded by the events at the World Trade Centre in 2001. The towers were structurally highly redundant, comprising a rigid perimeter frame and a gravity load bearing central core, together with a truss system installed between the $107^{\text {th }}$ and $110^{\text {th }}$ floors which linked the perimeter frame to the central core structure (Kirk, 2005). The towers remained globally stable immediately after the impacts, despite the severing of up to 36 perimeter columns in the face of each tower. The gravity loads originally carried by the damaged perimeter columns were partially transferred to the adjacent undamaged columns via vierendeel action. In addition, perimeter columns were also believed to have become suspended from the trusses installed between the $107^{\text {th }}$ and $110^{\text {th }}$ floors. It can be speculated that the buildings may have collapsed immediately following the impacts if the towers had not incorporated the trusses, although no research has been carried out to prove this.

Sasani and Sagiroglu (2008) carried out an experimental investigation of the robustness of the Hotel San Diego which had already been planned for demolition. The building featured a reinforced concrete frame structure with hollow clay brick exterior infill panels. The response of the building after a simultaneous removal of two adjacent exterior columns, one of which was a corner column, was recorded. The building successfully bridged the damaged areas, with loads redistributed through vierendeel frame action and diagonal strutting in the panel walling (Sasani and Sagiroglu, 2008)). 
A recent progressive collapse test was carried out on the 11-storey reinforced concrete Crowne Plaza hotel in Texas. Four columns were removed using explosive charges (Sasani, 2011). Two of the columns were on the centreline of the building perimeter and the two internal columns were immediately adjacent. The building was unloaded and was able to withstand the column loss with only a 50mm total displacement, and the load redistribution was assessed as being arching action in the floor plates, as well as Vierendeel action in the frame, which was constructed using insitu reinforced concrete.

\section{Codes and regulations}

The Ronan Point incident (1968) led to UK Building Regulations (BSI, 1997; BSI, 2000) which aim to ensure a minimum level of structural integrity and to changes to American and Canadian codes of practice (ASCE, 2002; NBCC 1995). None of these amendments attempted to control the progressive collapse assessment methods used to analyse frames following notional column removal. The need for control of the analysis procedures was highlighted both by the Oklahoma City bombing in 1995 and by the attack on the Twin Towers in 2001; events which influenced the introduction of progressive collapse assessment method guidelines by the US General Service Administration (GSA, 2003) and by the US Department of Defence (DOD, 2009).

Member tying. The general design guidelines and suggestions given in the commentary in ASCE 7 include: plan layout (including reducing long spans), integrated systems of ties, changing span directions of floor slabs, load-bearing interior partitions, catenary action of the floor slab, beam action of the walls, ductile detailing and the addition of reinforcements for blast and load reversal. British Standards (BS 5950 and BS 8110 (BSI 1997 and 2000)) and Eurocode 1 (CEN 2006) employ the tying force method to maintain continuity in an event of abnormal loading. For buildings such as 5 storey single occupancy houses and hotels not exceeding 4 storeys Eurocode 1 allows for only the provision of horizontal ties. For buildings such as hotels, flats, apartments and other residential buildings greater than 4 storeys but not exceeding 15 storeys, effective horizontal ties should be provided together with vertical ties in all supporting columns and walls. Alternatively, analysis can be carried out after notionally removing one load bearing member at a time (at each storey of the building) to check the extent of collapse progression, in addition to the provision of horizontal ties. As stated previously, the method of analysis for notional column removal is not stipulated.

Eurocode 1 (and British Standards) requires the building to be effectively tied around the perimeter of each floor and roof level and internally in two right angle directions so that the building structure can act together to avoid disproportionate collapse in an abnormal event. In the case of steel or reinforced concrete framed buildings, the code also requires load bearing columns and walls to be tied continuously from the foundation to roof level and to be capable of resisting an accidental design tensile force equal to the largest design vertical permanent and variable load reaction. 
Despite the fact that the tying force method is the easiest method to implement as it does not require additional analysis of the structure, the reliance on the tying force method to redistribute loads following localized damage in steel framed buildings has been questioned. Recent calculations of the factors of safety (Byfield and Paramasivam, 2007) illustrate that the codified procedure provides only a lower bound estimate of the tying force required to arrest the downwards movement of a damaged bay of the building as it ignores the dynamic amplification due to the additional force needed to absorb the kinetic energy. In addition, the inadequacy of rotational capacities of industry-standard connections to redistribute loads through catenary action in steel framed buildings has been highlighted (Byfield, 2004).

Alternative load path design methods. In the alternative load path design methods, the structure is designed in such a way that a new load path could be developed to bridge across the local failure zone. The alternative load path relies on the "robustness" of the structure (an attribute of a structural system that relates to its ability to fulfil its function in the face of adverse events (Agarwal, 2011)) achieved through continuity and ductility of members to redistribute forces following localized damage and directs designer's attention towards the behaviour of the structure after some damage has occurred. This method is a threat independent method and avoids designing for an extreme event of specific magnitude that may be exceeded during the service life.

The basic procedure in the alternative load path analysis given by ASCE, US GSA and US DOD involves analysing the damaged structure with a specific loading to check if the initial damage propagates. The damage is introduced by notionally removing one primary load bearing member at a time. The US GSA approach recommends middle of the long side, middle of the short side and the corner of the building, only at the ground level, as locations of column removal (one at a time) whereas the locations of column removal specified in the US DOD approach are the same but columns at each floor level should be considered. Four analytical approaches for alternative load path analysis are approved by the US GSA and the US DOD: linear static, nonlinear static, linear dynamic and nonlinear dynamic analysis.

The limitation of the alternative load path method lies in its requirement that only one key element at a time is to be removed to check the ability of the structure to redistribute loads without leading to a disproportionate collapse. One example that highlights this limitation is the partial collapse of the Alfred Murrah Federal building in 1995. The failure of three perimeter columns (2 in shear and 1 by brisance) would still trigger the same result even if the building had incorporated a mechanism to safely redistribute loads following removal of one load bearing column (Paramasivam, 2008). Another example is the collapse of World Trade Centre Towers (WTC $1 \& 2$ ) in 2001. The localized damage in the WTC1 by the impact of an aircraft was massive: at least 5 of the prefabricated wall sections and 31 to 36 columns were instantaneously destroyed (Corley, 2003). 
Specific local resistance methods. The basic concept behind the specific local resistance is to design any structural element over which the building cannot bridge as a "key" or "protected" element, capable of resisting a specific level of threat, which may be in the form of blast, impact or any other abnormal event. The limits of allowable collapse progression as given in many design codes and guidelines are tabulated in Table 1. The UK Building Regulations require that key elements should be designed to resist an abnormal load of $34 \mathrm{kN} / \mathrm{m}^{2}$ applied from any direction. This loading has also been incorporated into Eurocode 1 as a quasi-static accidental load which should be applied in horizontal and vertical directions (in one direction at a time). It is worth remembering that the $34 \mathrm{kN} / \mathrm{m}^{2}$ originates from an estimate of the over-pressure from the Ronan Point natural gas explosion. It will not provide protection against blast loading from vehicle-borne IED's, which can develop pressures that will dwarf this pressure, albeit for durations of only a few thousandths of a second. For example, $34 \mathrm{kN} / \mathrm{m}^{2}$ would not have provided protection to the (key element) columns supporting the transfer girder in the Murrah Building, which were subjected to a peak reflected pressures of the order of $10,000 \mathrm{kN} / \mathrm{m}^{2}$ following detonation of $1800 \mathrm{~kg}$ of home-made explosives at close range (Paramasivam, 2008).

The specific local resistance method is a threat specific design method and would typically be used for designing hardened structures like vulnerable areas of embassies, post rooms and explosive storage facilities. The main issue in this method is that the unforeseen nature of the abnormal event may lead to designing key elements with inadequate strength to resist a threat occurring in the future. The United States design guidelines mentioned previously provide no specific magnitude of the threat to be considered in designing key structural elements. Instead, the magnitude of the extreme load remains to be chosen by the engineering team and/or client. However, ASCE 7 guidelines help by specifying load combinations, suggesting other loadings with their respective load factors (i.e. wind load, snow load and live load) which can simultaneously act with the accidental load on structures.

It should be noted that many hardened structures have been subjected to blast loading and survived without significant structural damage. Instances include the US Embassy buildings in Nairobi and Dar-El-Salaam in 1998, which survived large bomb blasts without failing structurally, whereas some adjacent unstrengthened buildings suffered complete collapses. Buildings designed for seismic loading have also been shown to have a natural ability to resist blast loading without collapse. For example the seismically designed HSBC Building in Istanbul survived loading from a large IED in 2003 without significant damage to the frame.

On the other hand, the effectiveness of the combined approach given in the UK Building Regulations has been illustrated in a number of deliberate attacks on buildings (Moore, 2002). The Exchequer Court building was a steel framed structure with in-situ concrete floors acting compositely with a steel profile metal decking and located in St. Mary's Axe, London. In 1992, a high explosives detonation completely different to an internal gas explosion occurred $6 \mathrm{~m}$ away from the face of the 
building and badly damaged the cladding, columns, beams and floors close to the blast. Despite the considerable damage, the building remained stable (Moore, 2002). Since the building was over five storeys high, tying requirements at connections according to UK Building Regulations would have been provided to enhance the robustness of the structure to avoid any disproportionate progression of local damages.

\title{
3 Progressive collapse analysis procedures
}

The alternate load path method requires an assessment of the capacity of a frame to redistribute load away from damaged members. This requires the engineer to consider the most suitable analytical procedure, model complexity and design assumptions within the constraints of expense, computing power and time. In general, there are five procedures (Cormie et al, 2009) used to perform such an analysis:

\author{
i. Linear static using dynamic load factors \\ ii. Non-linear static using dynamic load factors \\ iii. Non-linear static pushover (energy balance procedure) \\ iv. Linear dynamic \\ v. Non-linear dynamic
}

Linear methods require the material response to remain in the elastic range and second order (P-delta) effects and instabilities to be ignored. This limits their use to small-displacements and often leads to conservative design in order to prevent invalidating the assumptions. Non-linear methods include material plasticity and are able to account for geometric non-linear effects as they become more significant, they also have the potential to allow for the development of alternative load path mechanisms, such as arching action or catenary action, Figure 1.

The United States General Service Administration guidelines (GSA, 2003) advise the use of three dimensional analytical models subject to a linear elastic or static analysis procedure, but two dimensional models may also be used. The potential for progressive collapse is assessed for the case of instantaneous column loss at a variety of floor levels for both interior and exterior columns. Once the column is removed the survivability of the individual elements is assessed using demand capacity ratios (DCRs). Where the DCR for any member end or connection is exceeded, based upon shear force, the element is considered to have failed and is removed from the analysis and all related loads redistributed. If a DCR is exceeded, based upon moment capacity, a hinge is inserted at the centre of yielding for the connection or member. This process is applied to all structural elements and then the entire process repeated with the modified frame model. If moments are redistributed throughout the structure but there are DCRs exceeded outside of the allowable collapse region, then the structure is considered to have a high potential for progressive collapse. 
Although not required for the static analysis, the removal time of the column can have an influence on the response of the structure during a dynamic analysis and the GSA guidelines take account of this by limiting the removal time to $1 / 10$ of the natural period of the removed element. An additional guide for preventing progressive collapse is the United States Department of Defence Unified Facilities Criteria (UFC) 4-023-03 "Progressive collapse analysis and design guidelines for new federal office buildings and major modernization projects". This document closely follows the approach of FEMA 273 (FEMA, 1997) by incorporating flow charts to check if the structure requires progressive collapse design, the level of which is related to the occupancy category of the structure. If it is found necessary to design for progressive collapse numerous methods are outlined which employ tying forces, alternate load paths, enhanced local resistance or a combination of all three. In general these methods use the load and resistance factor design approach with factors obtained from the ASCE/SEI design guidance. Three analysis procedures are employed; linear static (LSP), non-linear static (NSP) and non-linear dynamic (NDP). Demand capacity ratios are used, similar to GSA, to assess the capability of each structural element. Analytical models used to perform alternate load path analysis are discussed in the following section.

Both the DoD and GSA guidelines use similar scenario-based methods to aid designers in avoiding progressive collapse, however the $\mathrm{DoD}$ guidance also provides a tie force procedure to allow large deformations through catenary action (Ellingwood, 2009).

All of the methods are required to account for the dynamic inertial effects of the collapse. The simplest methods use dynamic load factors (DLF) to modify the dead and live loads in a static analysis. The DLF is the ratio of the dynamic to static load required to produce the equivalent static peak displacement and can normally range from 2 for an elastic system subject to instantaneous column loss to 1 for fire scenarios. In methods incorporating material non-linearity, calculation of the DLF is complicated by energy dissipation during the ductility phase where members achieve significant plastic rotations and deformations. In these cases a dynamic multiplier of 2 has been found to be conservative (Tsai and Lin, 2009) and a factor of 1.5 (Ruth et al, 2006) has been recommended to provide a realistic and economical approximation. UFC 4-023-03 presents a method to determine the DLF's for frames and recent structural testing by (Sasani and Sagiroglu, 2008; Sasani, 2011) where support to a column in a building was removed using explosive charges provides evidence that the DLF for reinforced concrete framed buildings may be close to the 1.1 to 1.15 range.

A non-linear static pushover procedure has been developed (Izzuddin, 2008) which does not require an estimation of load factors to predict the dynamic response. This technique is based upon the energy balance of the system, where the potential energy released by the column removal is compared against the energy absorption capability of the frame. The method allows analysis at various levels of structural idealisation, from a double span beam scenario to an entire bay of a multi-storey structure. The non-linear static response of the damaged system is calculated by gradually applying the gravitational loads in a static analysis. The static model can be created using either detailed or 
simplified models taking account of material nonlinearity and connection response. The resulting nonlinear load vs. peak displacement curve accounts for both elastic and plastic phases before either hardening (i.e. catenary action) or softening (i.e. local element failure). Once the nonlinear static response is established a simplified dynamic assessment is conducted by assuming the response is dominated by a single deformation mode (Biggs, 1964). This assessment procedure is used to transform the nonlinear static response into the maximum dynamic response by considering the energy balance between the work done by the load and the internal energy stored within the structure. As such, at the time of column removal the resistance is less than the applied gravity load and the structure accelerates. The difference between the work done and the internal strain energy is the resulting kinetic energy. At the point where the resistance becomes greater than the applied load more strain energy is generated than the work being performed and the kinetic energy is reduced eventually bringing the structure back to rest. The value of displacement is calculated such that the strain energy and work done are equal giving the maximum dynamic displacement. If there is insufficient area under the nonlinear static curve to balance the work done then the structure has not reduced the kinetic energy to zero and thus collapse is likely. If equivalence is achieved, the final stage is to perform a ductility assessment to ensure it remains within the limit state.

In a dynamic analysis the equations of motion are solved over discrete time steps which allow the complete time history response of the structure to be calculated. Because the dynamic effects are explicitly accounted for there is no requirement to define a dynamic load factor or calculate a pseudostatic response first. It is uncommon to perform linear dynamic analysis because of the inability to account for geometric nonlinearity and the requirement to stay in the elastic regime. In general either a non-linear static or non-linear dynamic procedure is preferable. In theory a full three dimensional computer model of a structure, including the connections which incorporated accurate material properties (including strain-rate effects) and exact loading conditions would precisely replicate the real response. This has been attempted for high priority structures such as the collapse of the World Trade Centre Towers (NIST, 2005). A model of the entire structure was created and analysed in stages using a variety of finite element packages. These included details such as the behaviour of furnishing materials under impact debris and the effect of strain-rate and temperature on structural elements. Also modelled was the aircraft impact in order to predict the initial structural damage. One advantage the investigative team had was the large archive of photographic and video evidence, the numerous technical documents describing the structures and the experimental data of the material properties that were obtained following the event. These data allowed the team to compare the test results against the real behaviour and verify each stage of the analysis.

All of these analysis methods have their advantages and disadvantages, as summarised in Table 2. In general the simpler procedures produce conservative designs but are easily verified. Conversely the more complicated methods allow a greater understanding of the real behaviour and often provide more economical designs, but require significant expertise to execute safely. A typical 
structure will require static and stability analyses prior to commission and therefore similarities for a dynamic load factor analysis can be used to provide an initial estimation of progressive collapse performance. Depending upon the level of robustness required these initial estimations can be followed by increasingly complex methods. This progressive analysis method (Marjanishvili, 2004) allows the results from each step to be compared against the previous whilst ensuring the appropriate level of complexity is achieved.

The modelling of connections during progressive collapse analysis. The most complete analysis guidelines to date include those published by the United States General Services Administration (GSA, 2003) and the United States Department of Defense (DoD, 2009) both of which identify methods of analyses which can be used for the alternate load path analysis. In comparison UK Building Regulations (ODPM, 2004) and Eurocodes (CEN, 2006) provide requirements and acceptance criteria but do not recommend specific computational methods. For all methods a difficulty arises with regard to modelling connection performance. For steel structures, it is widely accepted that connections are the most vulnerable elements within the structural system (Marchand and Alfawakhiri, 2004) and therefore careful consideration must be paid to their design to ensure a suitable level of ductility and robustness. The importance of connection performance was demonstrated by the analysis of bomb damaged multi-storey structures following the Second World War which led (Baker et al, 1943) to conclude "Most structural failures in steel-framed buildings can be traced to weakness in the connexions".

Frames with full-strength connections are relatively simple to model from a progressive collapse view point, whereas significant difficulties occur in frames with semi-rigid "nominally pinned" connections. Full strength connections have a design resistance at least equal to the plastic moment resistance of the supported member (Case A, Figure 2) and thus a plastic hinge will form outside the connection region. In some cases however strain hardening of the member could cause early connection yielding (Case B). Partial strength connections have a design resistance less than their connected members (Cases C, D and E). In these cases the supported member remains elastic and all rotation demands are supplied by the joints, thus the rotation capacity is of primary importance to the development of alternative load paths through catenary action. Where large rotations are a possibility, partial strength connections with limited rotational capacity (Case C) are to be avoided. The effect of prying action, where the beam flange makes contact with the column (Figure 3), must be included as this can influence the stiffness of the connection and lead to premature failure (Case E).

The US DoD (DoD, 2009) recognise this problem and require designers to "model a connection explicitly if the connection is weaker or has less ductility than the connected components". Incorporating semi-rigid behaviour into global structural analysis is necessary in order to accurately model joint failures which may progress to a collapse. The most complete way of achieving this is to use experimental data from connection tests, however the large number of connection types and 
variations mean suitable test data is not available for every design situation (Tsai and Lin, 2009; Izzuddin, 2010). Full 3D finite element models of connections have the ability to simulate accurate joint behaviour but require high levels of technical skill and computational expense. A simple alternative is the use of rotational hinges to account for nonlinear moment-rotation behaviour (Liu $e t$ $a l, 2010)$. Typical parameters include elastic/plastic moment-rotation stiffness, yield/ultimate strength and ultimate rotation. However reliable formulae for quantifying this performance for the vast number of connection typologies and configurations are often not available (BCSA, 2005).

For progressive collapse modelling, behaviour is further complicated by the presence of high axial loads and dynamic strain-rate effects where the rate of rotation has been shown to have a significant effect on connection performance (Tyas et al, 2011). The connection axial load capacity is commonly obtained from direct tension tests (Owens and Moore, 1992) which do not include connection rotation and subsequent prying action, meaning that the predicted axial capacity may be significantly greater than in reality. This problem has been the subject of recent investigations (Byfield and Paramasivam, 2008) where results indicate that many simple connections possess insufficient ductility to accommodate the large rotations that occur during catenary action. For these scenarios a single rotational hinge, or yield element, which does not take account of axial loads is usually deemed unsuitable. Ellingwood and Dusenberry (2005) note that knowledge of connection behaviour before, during and after extreme events is essential for accurate prediction of alternate load path development.

An alternative is to model the connection using an assembly of non-linear 'spring' elements representing each deformable region of the connection. This component-based method is similar to that detailed in Eurocode 3 Part1:8 (CEN, 2005) however instead of using the connection model to calculate the connection performance prior to analysis, the 'spring' elements are incorporated directly into the structural model and each active component makes its contribution to the overall behaviour independently through its structural properties. This allows the prediction of the load distribution and failure mechanisms within the connection and can account for all loading conditions including axial forces whilst maintaining global equilibrium of the system. This intermediate approach drastically reduces computational time compared to 3D FEA and allows the impact of variations of structural configurations to be investigated quickly. Very good results have been obtained for progressive collapse analysis (Izzuddin, 2008) as well as analysis of structures under elevated temperature conditions, where the effect on material properties can be included (Bayo et al, 2006; Spyrou et al, (2004) and Burgess et al (2005)). 


\section{Conclusions}

A range of factors have been shown to lead to progressive collapse, including accidental or deliberate impacts and explosions, design or construction errors, as well as poor maintenance. The Ronan Point event led to the UK pioneering regulations to ensure a minimum level of structural integrity. The Alfred P. Murrah Federal building collapse in 1995 and the Twin Towers in 2001 led to the US General Service Administration and the Department of Defence introducing the most comprehensive progressive collapse mitigation and modelling guidelines available to date. The regulations take two distinct forms: the indirect methods that dictate minimum levels of strength and continuity which were developed following Ronan Point; and the direct design methods that explicitly consider the extreme loads and the methods used to assess the response of the damaged structure following localised damage.

Five progressive collapse analysis procedures are discussed, ranging from linear static analysis with dynamic load factors, through too sophisticated non-linear dynamic analysis, which can account for material and geometric non-linearity. Linear-static procedures lead in general to conservative approximations and are popular because they minimise design time. The more sophisticated methods allow for a more realistic approximation of load redistribution and often provide more economical designs, but require significant expertise to execute safely, particularly with respect to the modelling of the beam to column connections.

The level of robustness in steel structures is significantly influenced by connection ductility, and the importance of connection performance to prevent structural failures has been demonstrated in the literature, through experimental and analytical studies. The semi-rigid nature of many popular connections can lead to prying action and early joint failure during progressive collapse. Therefore, incorporation of a methodology to capture true performance of semi-rigid connections in progressive collapse modelling remains a significant challenge, although advances in the use of the componentbased method can produce accurate results in progressive collapse analysis without requiring large computational resources.

\section{References}

Agarwal J (2011) Robustness of Structures: Lessons from successes and failures. Proceeding of the Final Conference of COST Action TU 0601. Prague, Czech Republic.

ASCE (2002), Minimum design loads for buildings and other structures. Reston, Va.

Baker JF, Williams ED and Lax D (1948) The design of framed buildings against high-explosive bombs. The Civil Engineer in War - W.E.P: Volume 3. p. p. 80-112, Institution of Civil Engineers, London.

Bayo E, Cabrero JM and Gil B (2006) An effective component-based method to model semi-rigid connections for the global analysis of steel and composite structures. Engineering Structures 28(1): p. 97-108. 
BCSA (2005) Steel details (Publication No 41/05). British Constructional Steelwork Association, London, UK.

Biggs JM (1964) An introduction to structural dynamics. McGraw-Hill Book Company, New York.

BSI (1997) BS 8110: Part 1: Structural Use of Concrete. BSI, London, UK.

BSI (2000) BS 5950: Part 1: Structural Use of Steelwork in Building. BSI, London, UK.

Burgess IW Plank RJ and Al-Jabri KS (2005) Spring-stiffness model for flexible end-plate bare-steel joints in fire. Journal of Constructional Steel Research, 61(12): p. 1672-1691.

Byfield MP (2004) Design of steel framed buildings at risk from terrorist attack. Structural Engineer, 82(22): p. 31-38.

Byfield MP and Paramasivam S (2012) The Murrah Building: A reassessment of the transfer girder. Journal of Performance of Constructed Facilities, No. 4, DOI: 10.1061/(ASCE)CF.19435509.0000227.

Byfield MP and S Paramasivam (2007) Catenary action in steel-framed buildings. Proceedings of the Institution of Civil Engineers. Structures and buildings, 160(5): p. 247-257.

CEN (2005) EN1993-1-8:2005. Eurocode 3: Part 1-8 - Annex J Design of Joints. BSI, London, UK.

CEN (2006) EN 1991-1-7:, Eurocode 1: Actions on Structures: Part 1-7 : Accidental Actions. BSI, London, UK.

Corley WG (2003) Structural investigation of the New York world trade centre collapse, in CIBCTBUH international conference on tall buildings, Malaysia, Publication No: 290.

Corley WG et al. (1998) The Oklahoma City bombing: summary and recommendations for multihazard mitigation. Journal of Performance of Constructed Facilities, 12: p. 100.

Cormie D, Mays G and Smith P (2009) Blast effects on buildings, 2nd edition. Thomas Telford Ltd, London, UK.

Davis (2007) Buda's wagon: a brief history of the car bomb. Verso Books.

DoD (2009) UFC 4-023-03: Design of buildings to resist progressive collapse. Department of Defence, Washington, D.C.

Ellingwood B et al (2009) Disproportionate Collapse Research Needs. ASCE Structures Congress, Austin, Texas, USA.

Ellingwood B, et al. (2007) Best practices for reducing the potential for progressive collapse in buildings. 2007. National Institute of Standards and Technology, USA.

Ellingwood BR and Dusenberry BO (2005) Building design for abnormal loads and progressive collapse. Computer-Aided Civil and Infrastructure Engineering, Volume 20, Number 3, pp. 194205(12).

FEMA (1997) Guidelines for the Seismic Rehabilitation of Buildings. Publication No. FEMA 273, Federal Emergency Management Agency: Washington DC.

GSA (2003) Progressive collapse analysis and design guidelines for new federal office buildings and major modernization projects. General Service Administration, Washington, D.C.

Izzuddin B et al (2008) Progressive collapse of multi-storey buildings due to sudden column loss, Part I: Simplified assessment framework. Engineering Structures, 30(5): p. 1308-1318.

Izzuddin BA (2010) Robustness by design - Simplified progressive collapse assessment of building structures. Stahlbau 79 p. 556-564.

Kirk JA (2005) The world trade centre collapse: Analysis and recommendations, in Civil and Environmental Engineering. Thesis, Master of Engineering, Department of Civil and Environmental Engineering, Massachusetts Institute of Technology: Massachusetts. 
Liu Y, Xu L and Grierson DE (2010) Influence of semi-rigid connections and local joint damage on progressive collapse of steel frameworks. Computer-aided civil and infrastructure engineering, 25 (Compendex) p. 184-204.

Marchand, K. , and Alfawakhiri, F. (2004). Facts for steel buildings No.2: Blast and progressive collapse. ASCE, Chicago.

Marjanishvili SM (2004) Progressive analysis procedure for progressive collapse. Journal of Performance of Constructed Facilities, 18(2): p. 79-85.

Martin R and Delatte NJ (2000) Another look at the L'Ambiance Plaza collapse. Journal of Performance of Constructed Facilities, 14: p. 160.

McGuire W (1992) Comments on L'Ambiance Plaza Lifting Collar/Shearheads. Journal of Performance of Constructed Facilities, 6(2): p. 78-85.

Moore DB (2002) The UK and European Regulations for Accidental Actions., National Workshop on Prevention of Progressive Collapse, National Institute of Building Sciences: Washington, DC.

NBCC (1995). National Building Code of Canada, Ottawa, Ont.

NIST (1995) Terrorist bombing, Murrah Federal Building, Oklahoma, 1995. See http://www.nist.gov/el/disasterstudies/blast/oklahoma_bombing_1995.cfm.

NIST (2005) Final report on the collapse of the World trade Center Towers. NCSTAR 1, USA.

ODPM (2000) The Building Regulations, Part A3 Disproportionate Collapse. Office of the Deputy Prime Minister, p. 47, London.

Owens GW and Moore DB (1992) The robustness of simple connections. The Structural Engineer, 70(3).

Paramasivam S (2008) Protective design against disproportionate collapse for steel and r.c. framed buildings PhD Thesis. Faculty of Engineering and the Environment, University of Southampton, UK.

Pearson C and N Delatte (2005) Ronan point apartment tower collapse and its effect on building codes. Journal of Performance of Constructed Facilities, 19: p.172.

Ruth P Marchand KA and Williamson EB (2006) Static equivalency in progressive collapse alternate path analysis: Reducing conservatism while retaining structural integrity. Journal of Performance of Constructed Facilities, 20(4): p. 349-364.

Sasani M (2007) Experimental and analytical progressive collapse evaluation of actual reinforced concrete structure. ACI Structural Journal November - December.

Sasani M (2011) Experimental and analytical evaluation of progressive collapse resistance of a fullscale structure following severe loss of load bearing elements. Applied Mechanics and Materials 82, p. 326-331.

Sasani M and Sagiroglu S (2008) Progressive collapse resistance of hotel San Diego. Journal of structural engineering, 134: p. 478.

Smith PP, Byfield MP and Goode DJ (2010) Building robustness research during World War II. Journal of Performance of Constructed Facilities, 24(6): p. 529-535.

Spyrou S et al. (2004) Experimental and analytical studies of steel joint components at elevated temperatures. Fire and Materials, 28: p. 83-94.

Sucuoglu H and Altin S (1994) Resistance mechanisms in RC building frames subjected to column failure. Journal of structural engineering, 120: p. 765.

Tsai MH and Lin BH (2009) Dynamic amplification factor for progressive collapse resistance analysis of an RC building. The Structural Design of Tall and Special Buildings, 18(5): p. 539-557. 
Tyas A, Warren JA, Stoddart EP, Davison JB, Tait SJ and Huang Y (2012) A methodology for combined rotation-extension testing of simple steel beam to column joints at high rates of loading. Experimental Mechanics, Volume 52, Issue 8, pp 1097-1109.

Wearne P (1999) Collapse: Why Buildings Fall Down. Channel 4 Books.

Wood J (2003) Pipers Row Car Park, Wolverhampton - Quantitative Study of the Causes of the Partial Collapse on 20th March 1997. SS\&D Contract Report to British Health and Safety Executive (HSE). 